\title{
Soja, glifosato y salud humana. Algunas evidencias en el Chaco Seco Argentino (1990 - 2012)
}

\author{
Soy, glyphosate and human health. Some evidence in the \\ Argentinian Dry Chaco Region (1990-2012)
}

\author{
Fernando Longhi ${ }^{1}$ \\ Consejo Nacional de Investigaciones Cientificas y Técnicas, Argentina \\ Sebastian Bianchi ${ }^{2}$ \\ Agencia Nacional de Promoción Cientifica y Tecnológica, Argentina
}

\begin{abstract}
Resumen
En las últimas décadas del siglo XX y las primeras del siglo XXI el Chaco Seco Argentino (conocido también como Chaco Salteño o Umbral al Chaco), atravesó un intenso proceso de deforestación asociado al avance de la frontera agropecuaria. El paquete soja transgénica-glifosato (su herbicida asociado) fue el principal protagonista de dicho proceso. En el amplio debate existente sobre los efectos del glifosato sobre la salud humana no es suficiente la evidencia epidemiológica sobre dicha relación. Estos son los principales aportes de esta propuesta, los cuales operan sobre bases estadísticas de mortalidad.
\end{abstract}

Palabras clave: soja; glifosato; salud humana; chaco seco argentino

\begin{abstract}
In the last decades of the 20th century and the first decades of the 21st century, the Argentinian Dry Chaco Region (also known as Chaco Salteño or Umbral al Chaco), went through an intense process of deforestation associated with the advance of the agricultural frontier. The transgenic soybeanglyphosate agrotechnological package was the main protagonist of this process. In the broad ongoing debate pertaining to the effects of glyphosate on human health, epidemiological evidence on this relationship is not enough. That is why this article focuses on the use of mortality statistics, and
\end{abstract}

1 Dr. en Ciencias Sociales. Investigador adjunto de Consejo Nacional de Investigaciones Científicas y Técnicas (CONICET) en el Instituto Superior de Estudios Sociales. Correo electrónico: fernandolonghi@hotmail.com https://orcid.org/0000-0003-4616-8960

2 Ingeniero mecánico Becario de la Agencia Nacional de Promoción Científica y Tecnológica en el Instituto Superior de Estudios Sociales. Correo electrónico: bianki_pda@hotmail.com https://orcid.org/0000-0002$1159-5287$ 
therefore, its main contribution will be to make a first approach to the study of the epidemiological profile evolution of the region associated with the use of said package.

Keywords: Soy; Glyphosate; Human health; Argentine Dry Chaco Region

\section{Introducción}

En las últimas décadas del siglo XX y las primeras del siglo XXI el Chaco Seco Argentino, conocido también como Chaco Salteño o Umbral al Chaco (mapa 1) ${ }^{3}$, atravesó un intenso proceso de deforestación asociado al avance de la frontera agropecuaria (Paolasso y Krapovickas, 2012). Dicho avance operó como resultado de la expansión de empresas agrícolas, mayormente extrarregionales, dedicadas a la producción de commodities (principalmente oleaginosas y entre ellas, soja transgénica fundamentalmente).

La magnitud de estas transformaciones es tal que la superficie implantada se incrementó entre el 2000 y el 2012 un 185\% (pasó de 756.000 ha a 2.152.000 ha). La que corresponde a los cultivos con soja transgénica pasó de 455.000 a 1.044.000 has (un incremento del 130\%). Paralelamente, en ese mismo lapso se deforestaron alrededor de 1,5 millón de ha.

Esto ha sido posible debido a la implantación de una agricultura moderna, altamente tecnificada, con importante utilización de insumos y vinculada a mercados globales, aplicada sobre un territorio históricamente marginado, que concentra la más alta proporción de población indígena del país, y donde los modos productivos (y de vida) locales, requieren del uso de grandes superficies de bosque. En este contexto, la relación entre soja transgénica, su socio inseparable (el glifosato) y la salud humana es amplia y polémica, no obstante existe evidencia científica importante -como se verá más adelante- que identifica los efectos nocivos del glifosato sobre la salud, evidencia que en estudios epidemiológicos en nuestro país no se ha puesto de manifiesto aun.

En este contexto, este trabajo busca caracterizar de qué manera cambió el perfil epidemiológico de las causas de muerte en la región. El análisis parte desde el año 1990, cuando todavía la soja transgénica no era predominante,

3 La región bajo estudio comprende una porción significativa del Chaco Seco y Subhúmedo occidental Argentino, correspondiente a diecisiete departamentos de cinco provincias argentinas: Almirante Brown, General Güemes (Chaco); Bermejo, Matacos, Patiño y Ramón Lista (Formosa); Anta, General José de San Martín, Metán, Orán, Rivadavia y Rosario de la Frontera (Salta); Alberdi, Copo y Pellegrini (Santiago del Estero); Burruyacú y Cruz Alta (Tucumán). 
y alcanza hasta el año 2012. Esta pregunta tiene su correlato en las siguientes hipótesis: a) los cambios en el perfil epidemiológico no fueron trascendentes; o b) hubo un cambio en el perfil epidemiológico de la población del Chaco Seco. La segunda pregunta, amparada bajo la hipótesis b) buscará entonces, bajo distintas herramientas metodológicas, detectar asociaciones entre el incremento de determinadas causas de muerte con la adopción de este nuevo cultivo. En los últimos años se ha abierto un áspero debate acerca de los efectos que dicho producto -y la batería de químicos asociados al nuevo paquete tecnológico- podría tener sobre la salud de las poblaciones humanas.

Mapa 1. Chaco Seco Argentino: ubicación geográfica y departamentos que lo integran

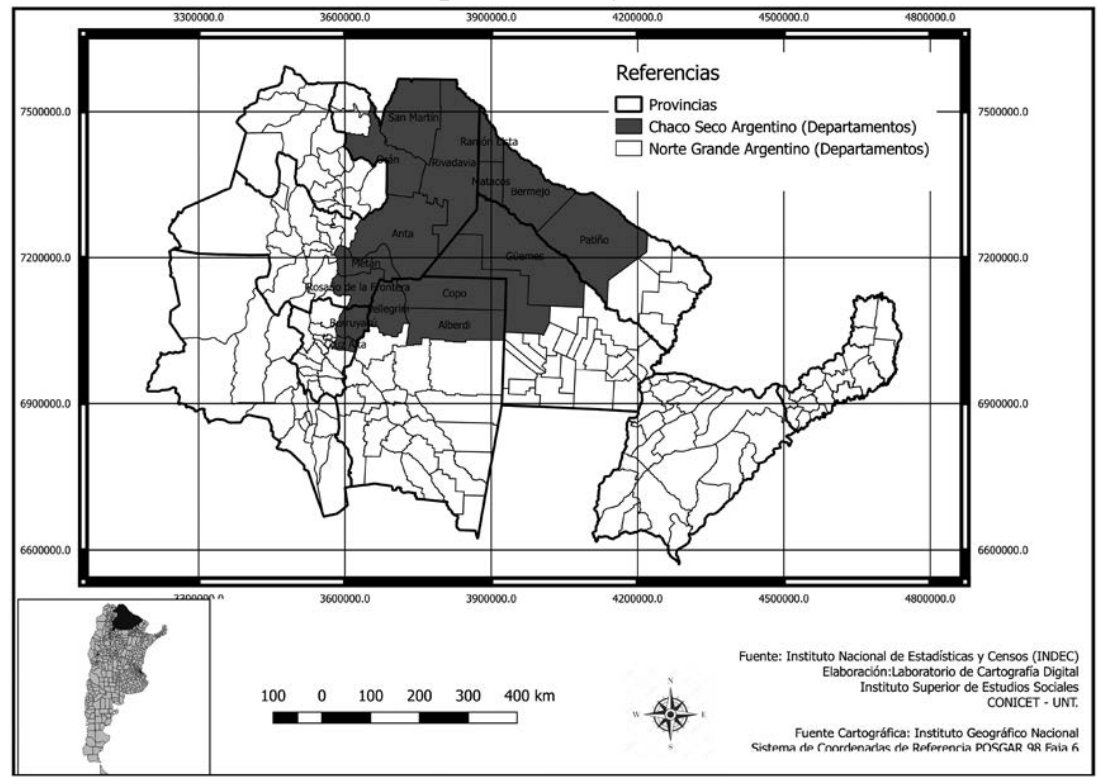

\section{Glifosato y salud humana ¿qué evidencias existen sobre esta relación?}

Sobre la relación que aquí nos ocupa existe un amplio y tenso debate. En los últimos años, la aparición de nuevos estudios independientes comienza a ampliar la información sobre los posibles efectos y relaciones entre algunos herbicidas y la aparición de ciertos tipos de cáncer. En un trabajo publicado en 1999 en el Journal of American Cancer Society por 
Hardell y Eriksson (Pengue, 2003) se revela la relación entre glifosato y Linfoma No-Hodgkin (LNH). Los investigadores sostienen -sobre la base de un estudio realizado entre 1987 y 1990 en Suecia-que la exposición al herbicida puede incrementar los riesgos de contraer esta enfermedad. En efecto, según Ibáñez (2002), el Roundup (nombre comercial del glifosato) se encuentra en varios países entre los primeros plaguicidas que causan incidentes de envenenamiento en humanos (Bravo et al., 2010). La mayoría de estos han involucrado irritaciones dérmicas y oculares en trabajadores, después de la exposición, durante la mezcla, carga o aplicación. También se han reportado náuseas y mareos después de la exposición, así como problemas respiratorios, aumento de la presión sanguínea y reacciones alérgicas Entre 1990 y 1995 se presentaron 33 demandas y 34 casos por intoxicación (Pengue, 2003). En California, el glifosato se encuentra entre los herbicidas más comúnmente reportados como causa de enfermedad o daños entre los trabajadores que manipulan herbicidas. Las presentaciones más comunes tienen relación con efectos oculares e irritación de la piel. Las autoridades norteamericanas recomiendan no reingresar por un período de 12 horas en aquellos sitios donde el herbicida haya sido aplicado en situaciones de control agrícola o industrial (Pengue, 2003).

En un plano más general, es conocido que desde las ciencias biológicas e ingenierías se suele utilizar el concepto "transgénico" para designar a todo organismo que ha sufrido modificaciones genéticas con el objetivo de aportarle determinadas características. En el caso específico de la denominada soja transgénica, la modificación que la semilla ha sufrido persigue un fin concreto, que es el de resistir la aplicación de un potente herbicida: el glifosato. Esto permite que los cultivos de soja transgénica fumigados con glifosato puedan desarrollarse sin la proliferación de hierbas no deseadas.

Los mayores avances en ingeniería genética aplicada a alimentos $^{4}$ se produjeron gracias al impulso que el descubrimiento del efecto

4 El objetivo de la ingeniería genética aplicada a organismos es la manipulación in vitro de del ADN de un ser vivo (bacteria, virus, vegetal, animal y humano), la introducción de este ADN así modificado en células vivas de otro organismo y la incorporación del mismo como parte del material hereditario de dichas células, que transmitirá las características deseadas. Para dimensionar el crecimiento de esta disciplina en las últimas décadas, se puede tomar como indicador el número de permisos otorgados por el Departamento de Agricultura de Estados Unidos (USDA) (país líder en ingeniería genética) para pruebas en campos con cultivos modificados genéticamente. Dicho número creció de 4 en 1985 a 1194 en 2002. Para septiembre de 2013, alrededor de 7800 nuevos permisos habían sido otorgados para maíz, más de 2200 para granos de soja, más de 1100 para algodón, y alrededor de 900 para papas. Los permisos para pruebas de tolerancia a los herbicidas fueron 6772 , en resistencia a insectos 4809 , calidad del producto como sabor o nutrición 
herbicida del glifosato le imprimió a partir de 1970. Dicho descubrimiento fue realizado por investigadores de la firma internacional Monsanto, empresa pionera y actual líder mundial en la modificación genética de células vegetales. ${ }^{5}$

Uno de los resultados de las investigaciones de Monsanto fue la semilla de soja transgénica denominada Roundup Ready, lanzada al mercado por primera vez en Estados Unidos en 1996 luego de ser aprobada por la Agencia de Protección del Medio Ambiente de ese país (EPA, por sus siglas en inglés).

A partir de su incorporación al mercado mundial, la utilización de dicha semilla ha crecido exponencialmente reemplazando casi en su totalidad a las semillas tradicionales de soja en aquellos grandes países productores de este alimento. Según los datos del ISAAA (International Service for the Acquisition of Agro-Biotech Applications) en el año 1998 el porcentaje de soja producido con semillas transgénicas respecto a la soja tradicional era del 20\%, mientras que en el año 2017 el mismo ascendía a 77\%, con un máximo del 82\% en el año 2015 (ISAAA, 2017). Los tres principales productores mundiales de soja transgénica son Estados Unidos con un 36.2\% del total mundial de hectáreas sembradas, Brasil con un 35.8\% y Argentina con un 19.2\% (ISAAA, 2017). Entre los tres países suman más del 91\% del total de superficie mundial sembrada con este cultivo. ${ }^{6}$

En Argentina, la primera campaña en la que se cultivó soja transgénica fue en 1996/97 (Rodríguez, 2010), desde entonces, esta producción ha ascendido sustancialmente, alcanzando en 2017 las 18.100.000 de hectáreas cultivadas, constituyendo en su totalidad soja transgénica (ISAAA, 2017). ${ }^{7}$

4896, propiedades agronómicas como resistencia a sequías 5190 y resistencia a virus y hongos 2616. Las instituciones con mayor número de autorizaciones son Monsanto con 6782, Pioneer/DuPont con 1405, Syngenta con 565, y el Servicio de Investigación Agrícola del Departamento de Agricultura de Estados Unidos con 370. Para esa fecha, el Departamento de Agricultura había recibido propuestas para habilitar campos para arroz, chayote, ciruela, tabaco, lino y achicoria genéticamente modificados (Fernandez, Wechsler, Livingston, \& Mitchell, 2014).

5 Asimismo, el papel de Monsanto en la industria química fue y continúa siendo principal, sustentado en el diseño y fabricación de productos químicos como el insecticida DDT o los herbicidas Agente Naranja y Roundup (cuyo principio activo es el glifosato).

6 En el año 2017 la proporción de superficie de soja transgénica respecto al total de soja sembrada en Estados Unidos fue del 94\%, mientras que en Brasil fue del 97\% (ISAAA, 2017).

7 Es claro además el dominio de la soja entre la producción transgénica argentina: sobre un total de 23.6 millones de hectáreas sembradas con cultivos transgénicos en 2017 , el $77 \%$ fueron de soja el $22 \%$ de maíz y el 1\% de algodón (ISAAA, 2017). 
No obstante esto, el proceso de sojización del territorio argentino había comenzado su etapa expansiva en la década de 1970, mucho antes de la llegada de la soja transgénica; sin embargo, con la irrupción de esta última la superficie total sembrada con soja de primera (único cultivo anual en esa superficie) creció de manera abrupta, pasando de 3.500.000 has en la campaña 1996-1997 a 9.500.000 has en 2004-2005 (Rodríguez, 2010). Este proceso no fue uniforme, ni en ritmo, ni en las formas adoptadas en su expansión en los distintos territorios del país. Comenzó su desarrollo en la región pampeana, donde se expandió a través de la sustitución de los tradicionales cultivos de trigo, maíz, girasol, y del desplazamiento de la ganadería hacia nuevas regiones. ${ }^{8}$ Sin embargo, en regiones extra-pampeanas, sobre todo en el norte del país, la forma de expansión fue diferente. Allí se desarrolló un proceso de pampeanización del agro, en el cual se impusieron los usos del suelo de la región pampeana sustituyendo a cultivos extrapampeanos como el algodón y el arroz (Rodríguez, 2010) e impulsando la agriculturización por deforestación ${ }^{9}$. Entre los años 1988 y 2011 la superficie cultivada con soja en el norte del país creció un $12 \%$ anual en promedio, pasando de 280.000 has a 2.680.255 has a fines del período (Ortega, 2014). Sin embargo, se pueden observar diferencias en la expansión a escala subregional. En la provincia de Chaco se percibe claramente la expansión de la frontera agrícola, por un lado basada en la deforestación, pero también por medio del reemplazo de cultivos preexistentes como el algodón. ${ }^{10}$ En cambio, en la provincia de Santiago del Estero y el oeste de

8 Nótese la magnitud de la tasa de crecimiento de la superficie sembrada con cereales en la región pampeana en el período 1970-2000, de una magnitud de 1,007 decreciente, mientras que la de las oleaginosas fue de 6,620 creciente (Pizarro, 2003).

9 Este proceso, que Bruniard (1975/78) llamó "pampeanización del Chaco", se asoció principalmente con las explotaciones de mayor tamaño. Las excluidas fueron las pequeñas pues el reemplazo significaba menor rentabilidad por unidad de superficie, aún con el creciente descenso de los precios del algodón. El efecto inmediato fue la reducción del 30 por ciento de la superficie sembrada con algodón entre 1960 y 1970. Cabe mencionar además que entre 1998 y 2002 se registraron 618.500 has desmontadas en las provincias de Salta, Chaco y Santiago del Estero en conjunto, un valor equivalente al $79 \%$ de los desmontes totales en Argentina. En el período 2002-2006 en las mismas provincias se desmontaron 1.057.600 has, correspondiendo al $89 \%$ del total del país (Ortega, 2014).

10 Entre los años 1988 y 2002, la superficie dedicada a cultivos en la provincia de Chaco se incrementó en un $66.8 \%$, pasando de unas 700.000 has a más de 1 millón. Este incremento se ha dado en gran parte sobre el monte nativo (solamente entre 1998 y 2002 la provincia perdió 117.000 has de montes), pero también por la sustitución de actividades agropecuarias preexistentes como el cultivo de algodón por cultivos transgénicos (soja y algodón). En el caso de la soja, ha pasado de 14.000 ha en 1988 a ocupar más de 640.000 ha en 2002 (Domínguez \& Sabatino, 2010). 
Chaco, el proceso de agriculturización fue enteramente desarrollado sobre áreas deforestadas y tuvo como único protagonista al cultivo de soja. ${ }^{11}$

Puede observarse entonces, que a pesar de que el proceso de sojización comenzó casi tres décadas antes de la llegada de la soja transgénica al país, ésta impulsó fuertemente la expansión de la superficie destinada a dicho cultivo y de la mano de este proceso se consolidó el glifosato como el herbicida más utilizado en el territorio argentino. Según Gómez Lende (2017) el consumo de agrotóxicos en Argentina aumentó un $858 \%$ entre 1991 y 2012, pasando de 39 millones de litros/año en 1991 a 335 millones de litros/año en 2012, e incluso en algunas provincias el volumen aplicado fue de cuatro a seis veces el permitido en otros países. Otro informe indica que el volumen de pesticidas aplicados en Argentina en 2013 fue de 281 millones de litros, de los cuales un 65\% fue glifosato (Bravo, 2015). A pesar de las variaciones en los datos, es claro que el volumen de glifosato aplicado es de una magnitud considerable y que exige un estudio profundo sobre sus posibles efectos en el medio ambiente y la salud humana.

En este contexto de consolidación de la actividad sojera transgénica se reconoce la existencia de un importante debate sobre los efectos nocivos del uso del glifosato en la salud humana, es sobre dicho debate donde pretende profundizar el presente artículo.

A nivel internacional, en 1993 la EPA y la Organización Mundial de la Salud (OMS) clasificaron al glifosato como agente de baja toxicidad, clase III (en una escala que va del I, mayor toxicidad, al IV) (EPA, 1997). En el año 2000 la EPA realizó una revisión de esta categorización y se concluyó que no presentaba riesgos para la salud humana (Williams, Kroes, \& Munro, 2000). A su vez, la Unión Europea en noviembre de 2017 determinó la extensión del permiso de utilización del glifosato por cinco años más, luego de una evaluación científica que determinó que "el glifosato no provoca cáncer" (Unión Europea, 2017: 1). Sin embargo, la OMS en su última revisión en marzo de 2015 lo catalogó como "probablemente cancerígeno en humanos y cancerígeno en animales (Grupo 2a)" (IARCOMS, 2015: 1), que es la segunda en gravedad.

En el orden nacional, por una resolución de la entonces Secretaria de Agricultura de la Nación, Argentina autorizó en 1996 a través de la

11 "En la campaña 2002/2003, [...] el 80\% de la agricultura (con la soja como principal cultivo) se hizo sobre áreas que en 1988 tenían vegetación natural” (Ortega, 2014, págs. 47-48). 
Resolución 167/1996 la producción y comercialización de las semillas de soja transgénica y los productos y subproductos derivados de éstas (Rodríguez, 2010). En cuanto al glifosato, el máximo órgano estatal de control de productos fitosanitarios (SENASA), permitió por primera vez su utilización en el país en 1977 y revalidó el permiso en $1999^{12}$ siguiendo los parámetros y la clasificación de la Organización de las Naciones Unidas para la Agricultura y la Alimentación (FAO, por sus siglas en inglés) y la OMS.

En el año 2009, el Poder Ejecutivo Nacional creaba la Comisión Nacional de Investigación sobre Agroquímicos (CNIA) ${ }^{13}$ y un Consejo Científico Interdisciplinario en el ámbito del CONICET (Consejo Nacional de Investigaciones Científicas y Técnicas), que debía realizar una evaluación minuciosa de los trabajos científicos nacionales e internacionales referentes a los efectos del glifosato sobre la salud humana y el ambiente y presentar sus conclusiones. El informe publicado en julio del año 2009 concluyó que, si se aplica responsablemente, el uso del herbicida no presenta riesgos para la salud humana o el medio ambiente (CNIA, 2009).

En contraste con los estudios e informes presentados por instituciones estatales y organismos internacionales, existen diversos estudios sobre los efectos del glifosato en la salud humana realizados por investigadores independientes en colaboración con organizaciones sin fines de lucro, que comprobarían la existencia de un vínculo entre el herbicida y enfermedades como el cáncer, alteraciones genéticas, abortos espontáneos, entre otras. En el contexto nacional Carrasco (2010) comprobó los efectos nocivos del glifosato en embriones de vertebrados, produciendo alteraciones en su morfogénesis. Estos resultados permiten suponer efectos similares en embriones humanos, sobre todo teniendo en cuenta que estudios previos han demostrado que el riesgo de alteraciones inducidas por el medio ambiente en el desarrollo humano es mayor durante el período crítico de gestación ( 2 a 8 semanas) y que la placenta humana es permeable al

12 Resolución 350/99 SENASA.

13 Órgano dependiente del Ministerio de Salud de la Nación, cuyos objetivos eran investigar los hechos denunciados, sus causas y efectos y reunir información estadística para poder coordinar e implementar acciones concretas desde el Estado. Dicha comisión prestaba especial atención a la denuncia por parte de vecinos de un barrio periférico de la ciudad de Córdoba (caso conocido como Barrio Ituzaingó Anexo), en la cual se exponían los efectos nocivos que el glifosato, pulverizado en las plantaciones aledañas al barrio, habría provocado en la población. 
glifosato (Carrasco, 2010). ${ }^{14}$ Del mismo modo (Benachour \& Seralini, 2009) comprobaron que los otros componentes adyuvantes de la fórmula Roundup no son inertes, y que pueden causar daños o incluso la muerte de células humanas umbilicales, embrionarias o de placenta. Asimismo, existen evidencias que corroboran la relación entre el glifosato y el linfoma de células B, los cuales incluyen tanto a los linfomas Hodgkin como a los no-Hodgkin (Schinasi \& Leon, 2014). Lo nocivo del producto fue expuesto también por Samsel y Seneff (2013), quienes demostraron que el glifosato inhibe la enzima CYP, cuyas consecuencias pueden ser trastornos gastrointestinales, obesidad, diabetes, enfermedad del corazón, depresión, autismo, infertilidad, cáncer y la enfermedad de Alzheimer. La evidencia se extiende también hacia el efecto genotóxico del glifosato sobre linfocitos humanos (Álvarez, y otros, 2014), como así también sobre el ADN de hígado y sangre de ratones, los cuales presentaron daños significativos en su estructura tras la exposición al glifosato (Mañas, y otros, 2013).

Se puede observar entonces que existen una serie de estudios que comprobarían los efectos nocivos del glifosato en la salud humana, principalmente desde las ciencias médicas y biológicas, pero que aún el posible efecto nocivo del producto no ha sido abordado desde una perspectiva epidemiológica y social.

\section{Precisiones metodológicas}

Para el abordaje propuesto se siguieron los lineamientos metodológicos que se enumeran a continuación:

a) Análisis bibliográfico. Con el objeto de conformar un marco conceptual que permita poner en debate las distintas investigaciones sobre la relación entre glifosato y salud se analizaron los antecedentes sobre este problema, tanto desde las ciencias médicas y biológicas como desde las sociales. Esto permitió individualizar, por un lado, causas específicas de muerte presuntamente asociadas al uso del glifosato y, por otro, niveles de aplicación y uso del mismo inferidos a partir de variables agrícolas.

14 En la misma línea, Anadón y otros (2009) estudiando la toxicocinética del herbicida determinaron, por un lado, que una vez ingresado el glifosato al organismo tiene la capacidad de llegar a la mayoría de los tejidos por su alto volumen de distribución y, por otro lado, que tiene una lenta eliminación del organismo, lo que le permite entrar en contacto con los tejidos el tiempo suficiente como para producir efectos sistémicos. 
Fue de singular importancia distinguir aquellas causas de mortalidad que ocupan mayor relación con el glifosato en la bibliografía. Se destacaron como principales a los tumores, malformaciones congénitas, alzheimer. abortos espontáneos y linfoma no hodgkin; y como secundarias al autismo, celiaquía, enfermedad renal crónica, depresión y parkinson.

b) Procesamiento de las bases de datos. Una vez definidas las variables a observar, fue necesario confeccionar y/o depurar las bases de datos que se utilizaron para el análisis estadístico. Se trabajó con las Estadísticas Vitales 1990-2012 y, desde el aspecto agrícola-territorial, con los Censos Nacionales Agropecuarios 1988, 2002, 2008, las Encuesta Nacional Agropecuaria (ENA) 2000, 2001, 2005, 2007 y las bases de Producción Agropecuaria 2009-2012, consultándose además bases de datos de cada distrito, integrando la información a través de un Sistema de Información Geográfica (SIG) que permitió identificar, analizar y exponer de forma clara los patrones de distribución de los perfiles epidemiológicos de las poblaciones analizadas.

c) Análisis estadístico. Se definió un Índice de Riesgo en Salud por Glifosización (IRSAG), el cual conjuga el efecto de una variable de riesgo con una de exposición, y se clasificaron, sobre la base de éste, cinco niveles o grupos departamentales de riesgo/exposición, para luego calcular tasas específicas de muerte para cada uno de dichos niveles. Luego, con el objetivo de observar cambios o permanencias en los perfiles epidemiológicos de las áreas de estudio, se analizó la evolución en todo el período de la tasa de mortalidad según niveles IRSAG y causas de muerte, y se compararon tanto valores absolutos entre niveles, como cambios en los ritmos de crecimiento de las tasas de mortalidad por medio de regresiones lineales.

\section{EI área de estudio y los niveles de sojización}

El Chaco Seco constituye una vasta llanura sedimentaria, modelada esencialmente por la acción de los ríos Juramento-Salado, Bermejo y Pilcomayo que la atraviesan en sentido noroeste-sudeste. Sus altas cuencas se encuentran fuera de la región, en la cordillera, desde donde transportan una gran cantidad de sedimentos que forman albardones a los costados del 
cauce o bien colmatan los cauces y dan origen a la divagación de los ríos (Torrella y Adámoli, 2005).

El Chaco fue siempre una región marginal, poco conocida y poco dominada por el control estatal, aunque no por ello menos codiciada. La ocupación y dominación del territorio representó grandes esfuerzos para los poderes centrales (primero coloniales y luego del Estado Argentino). La empresa no fue nada fácil, tal como lo relatan las crónicas de las primeras entradas (ya sean estas exploratorias, misionales o militares) (Paolasso y Krapovickas, 2012). Desde fines del siglo XIX se produjo la efectiva ocupación del territorio por el hombre blanco, la que se fue generalizando con diversos proyectos de colonización y el ingreso masivo de pequeños ganaderos de otras zonas del país, que se convertirán en los actuales puesteros criollos (Van Dam, 2002). De esta manera, durante la mayor parte del siglo XX el Chaco atrajo a pequeños productores ganaderos que se asentaron uniformemente en la región y con la llegada del ferrocarril se fundaron pequeños pueblos en las estaciones. Sin embargo, la escasez de infraestructuras, la baja densidad de población y los condicionamientos ambientales continuaron marginando a la región hasta el último cuarto del siglo pasado.

En términos productivos, tuvo una tradición profundamente ganadera sobre la que también operó el extractivismo forestal ${ }^{15}$. Desde 1970, sin embargo, se asiste a un proceso de avance de la frontera agraria sin precedentes en la región. El mismo se enmarca en las nuevas tendencias de carácter global inauguradas por aquel entonces, tales como la revolución tecnológica y científica, la reestructuración de los Estados, la privatización de actividades productivas y de servicios y la globalización de la economía mundial. Después de la segunda guerra mundial, el crecimiento de las ramas agroalimentarias y agroindustriales modificó sustancialmente

15 La explotación forestal se practicó históricamente como una extracción minera y no como el aprovechamiento sustentable de un recurso renovable. Esto llevó a que las especies más buscadas vieran diezmadas sus poblaciones y que llegaran muchas veces al límite de la extinción comercial, que difiere de la extinción biológica porque en ella la especie está presente, pero no en diámetros ni en volúmenes comercializables. Una de las especies más afectadas tanto por la explotación forestal como por la ganadería fue el quebracho colorado santiagueño. Por la dureza de su madera fue una de las primeras especies en ser explotadas comercialmente, al punto de que en vastas extensiones perdió su carácter de dominante en el bosque, y han quedado prácticamente sólo sus "tocones" muertos en el piso. Además, la renovación de sus poblaciones se ve afectada por la ganadería en distintos aspectos: sus renovales son preferidos por el ganado por sobre otras especies leñosas; sus ejemplares jóvenes son deformados por el ramoneo; y el mantillo de hojarasca que naturalmente actúa favoreciendo su germinación es eliminado (Torrella y Adámoli, 2005). 
las estructuras productivas y sociales agrarias de la mayoría de los países (Giarracca y Teubal, 2006).

Así pues, en Argentina, tierras consideradas "marginales" para el modelo de agricultura industrial asentado sobre la pampa húmeda comenzaron a ser de interés para grandes productores agropecuarios y fondos de inversión volcados al agro, principalmente a partir de la última década del siglo pasado (Teubal, 2006). Desde 1996, con la aparición en el mercado argentino de las semillas de soja transgénicas, el llamado "proceso de modernización" de la agricultura, basado en la utilización de semillas mejoradas, agroquímicos y maquinaria de alta capacidad operativa comenzó a hacerse más evidente (Rofman, 1999).

Este avance es, sin dudas, el proceso de mayor impacto sobre el paisaje y la mayor amenaza para la conservación de la biodiversidad de la región en la actualidad. Opera sobre la base del desmonte de grandes extensiones de bosques y, al hacerse sin una regulación o un plan ambiental de manejo, implica la pérdida y la fragmentación de ambientes y hábitats, lo que pone en peligro la conservación de la biodiversidad y la sustentabilidad del proceso.

En la figura 1 se observa la evolución de la producción de soja en esta región desde la campaña 1990/91 hasta 2017/18. Nótese el crecimiento constante durante estas tres décadas, llegando a representar la producción del Chaco Seco el 6.7\% de la producción sojera nacional en el año 2008 con aproximadamente 7 millones de toneladas producidas. Si se compara esta producción con la provincia de Córdoba, aquella con mayor producción de soja de la Argentina, se distingue el paralelismo y la simetría -salvando las magnitudes- entre ambos contextos territoriales. 
Figura 1. Áreas seleccionadas. Evolución de producción de soja (Tn). $1999 / 2018$

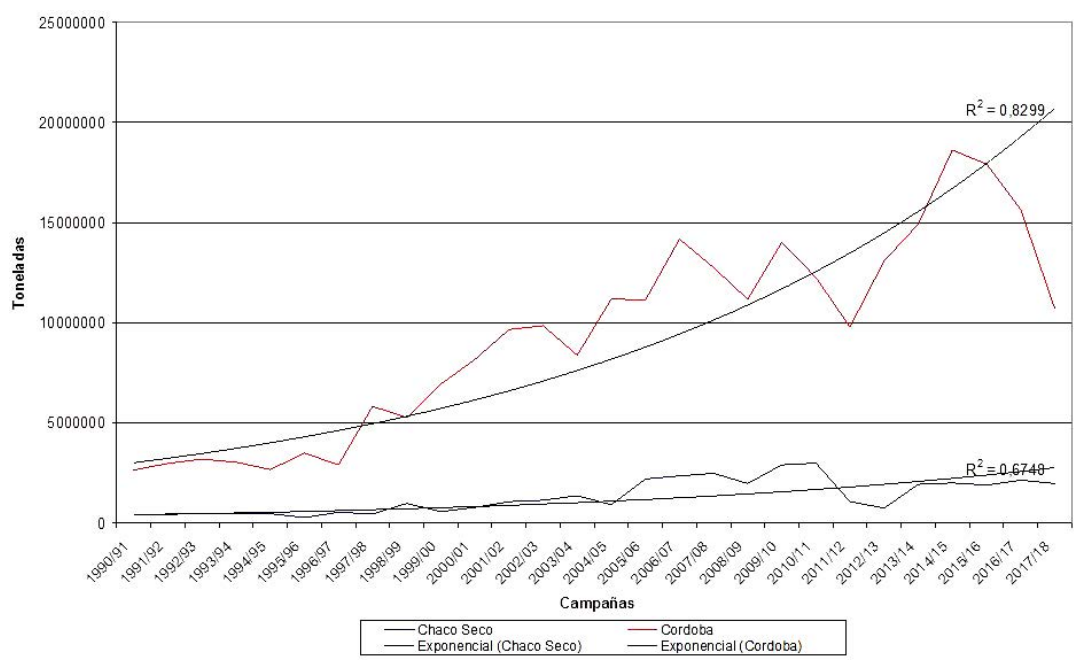

Fuente: Ministerio de Agricultura, Ganadería y Pesca. Datos y estimaciones agrícolas. http://datosestimaciones.magyp.gob.ar/

Este proceso de expansión de la agricultura extensiva, ha sido caracterizado por un uso masivo de insumos químicos y maquinaria potente y sofisticada, donde los primeros -asociados al uso de glifosato- podrían tener consecuencias sobre la salud humana, o mejor dicho, sobre las 951.443 personas que se asientan sobre esta área según el Censo Nacional de Población, Hogares y Viviendas del año 2010. Es esta conjetura la que guía el ejercicio posterior donde, a partir de dos variables: a) la proporción que representa la superficie implantada con soja respecto a la superficie departamental (variable de riesgo), y b) la población total promedio del departamento entre los años 1991, 2001 y 2010 (variable de exposición), se calculó -mediante el producto de ambas variables- el Índice de Riesgo en Salud por Glifosización (IRSAG). Una vez calculado este valor fue necesario realizar una tipología según niveles del IRSAG, para ello se detectaron quiebres naturales ${ }^{16}$ en la distribución de la variable, definiendo los cinco niveles que se observan en el mapa 2:

16 Este método calcula las diferencias de valores entre los individuos estadísticos ordenados de forma creciente. Luego coloca un límite para separar los grupos donde las diferencias de valores son mayores, y así determinar los límites de cada clase o intervalo. Los cortes de clase se caracterizan porque agrupan mejor los valores similares y maximizan las diferencias entre clases. 
Mapa 2. Chaco Seco Argentino. Niveles del Índice de Riesgo en Salud por Glifosización (IRSAG) y centros poblados 2010 según tamaño demográfico.

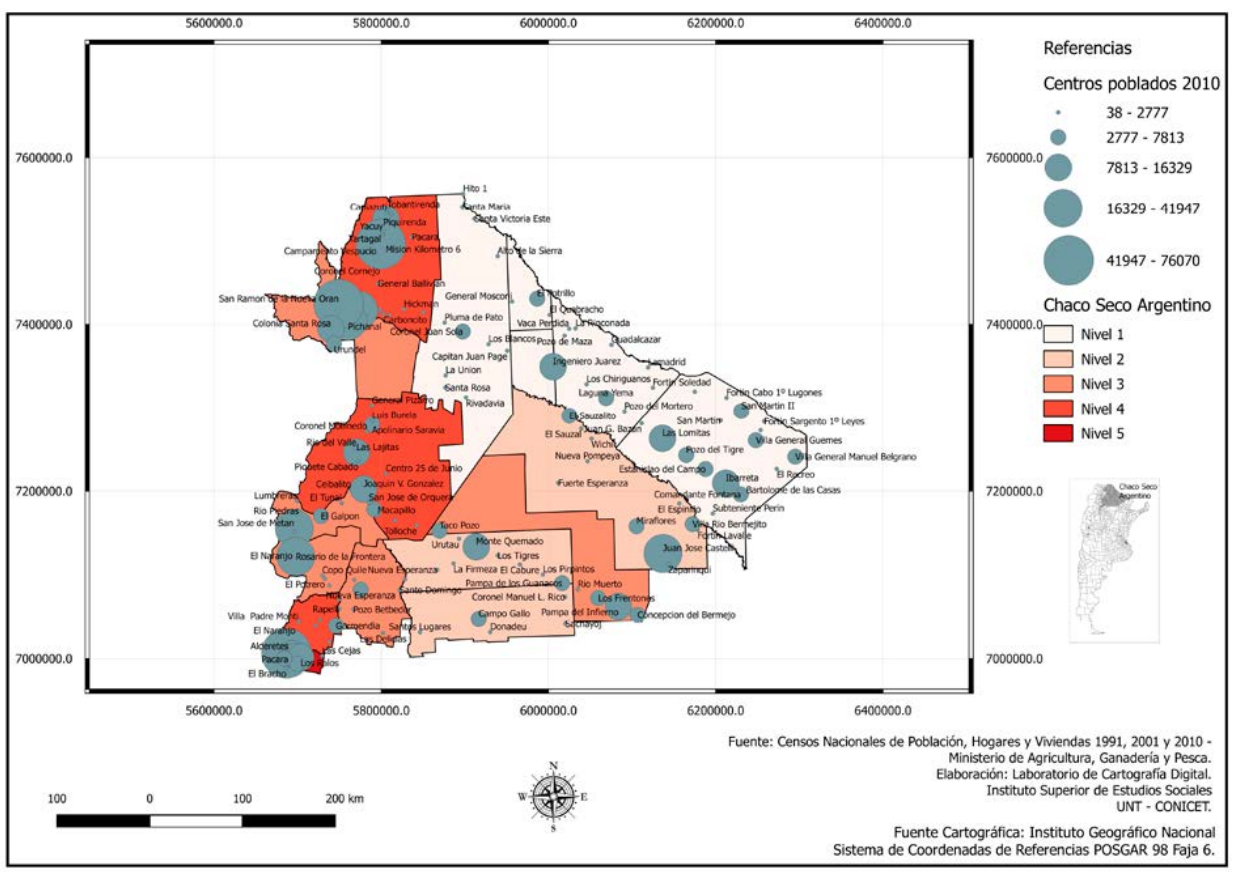

Asimismo, en la tabla 1 se sintetiza el peso demográfico según los niveles definidos.

Tabla 1: Chaco Seco Argentino. Total de población y proporción según niveles de IRSAG. (1990-2012)

\begin{tabular}{|c|c|c|c|}
\hline Nivel IRSAG & $\begin{array}{c}\text { Cantidad de } \\
\text { departamentos }\end{array}$ & Total de Hogares & $\begin{array}{c}\text { Proporción de } \\
\text { hogares respecto al } \\
\text { total del Chaco Seco }\end{array}$ \\
\hline I & 5 & 141113 & 14.8 \\
\hline II & 3 & 115788 & 12.2 \\
\hline III & 5 & 262771 & 27.6 \\
\hline IV & 3 & 251272 & 26.4 \\
\hline V & 1 & 180499 & 19.0 \\
\hline Total Chaco Seco & 17 & 951443 & 100.0 \\
\hline
\end{tabular}

Fuente: Censo Nacional de Población, Hogares y Viviendas 2001.

Ministerio de Agricultura, Ganadería y Pesca. Datos y estimaciones agrícolas. http://datosestimaciones.magyp.gob.ar/. Elaboración propia. 


\section{El perfil epidemiológico regional: estructura y dinámica}

El estudio de las causas de muerte ha sido frecuentemente utilizado para dar cuenta del grado y características del sistema de salud de determinadas áreas. En el caso de nuestro estudio, el Chaco Seco se configura como una de las áreas más pobres de la Argentina según distintos indicadores de bienestar. Una rápida mirada sobre la concentración de hogares pobres detenta, por ejemplo, en esta región un $27.1 \%$ de hogares con NBI en el año 2010, mientras el promedio nacional alcanzaba en la misma fecha al $9.2 \%$ de la población.

Lo caracteriza también el grado de variabilidad interna de este indicador, donde los extremos lo representan Ramón Lista y Rosario de la frontera, el primero con $68.1 \%$ de hogares pobres mientras el segundo incluye al $14.8 \%$ de sus hogares bajo esta condición.

Gran parte de la actual carga de patologías y causas de muerte que presenta el Chaco Seco pueden asociarse al estadio que ocupa dentro del modelo de transición epidemiológica. Este último sostiene una evolución desde la prevalencia de causas infecciosas de carencias nutricionales hacia un estadio donde dominan las enfermedades crónico-degenerativas o enfermedades crónicas no transmisibles (ECNT) (Frenk et al., 1991).

Como insumo para el estudio de dicha transición, es de vital importancia la calidad del registro de la información, principalmente las causas de muerte. En nuestro país, en relación al mencionado registro, existe gran preocupación respecto a dicha calidad, ya que constituye la principal fuente para obtener información sobre la morbilidad/mortalidad de la población y las características de su perfil epidemiológico, como así también el grado de avance en su transición epidemiológica; a su vez, es un dato esencial para la formulación de programas y políticas de salud. ${ }^{17}$

Para analizar estadísticas de mortalidad por causas es necesario contar con un instrumento que permita organizar todas las causas registradas

17 En este sentido Córdoba et al. (1989) presentan tres grandes limitaciones del registro de la causa de muerte:

a) La capacitación en el registro, pasando desde la información relevada por personal médico en algún hospital al registro realizado por personal sin ningún tipo de entrenamiento médico.

b) La distinta naturaleza de los padecimientos que conducen a la defunción; esto está relacionado con las diferentes etiologías, tiempos de evolución, grados de letalidad, etc., lo cual puede de alguna manera encubrir la causa básica de la defunción.

c) El variado mosaico de contextos en el que transcurre la vida y la muerte de una población, lo cual conduce a considerar los contextos socioculturales en los que estos ocurren; de esto se deduce la posibilidad de defunciones o nacimientos no registrados o mal registrados. 
en el certificado médico de defunción. La Clasificación Internacional de Enfermedades (CIE) satisface este requisito, ya que es útil para almacenar las causas registradas en los certificados de defunción en forma sintética. Esto permite recuperar esa información y facilita su análisis, interpretación y la comparación entre diferentes regiones o épocas. La CIE se define a sí misma como un sistema de categorías a las cuales se asignan entidades morbosas. Si bien el número de categorías es limitado y son mutuamente excluyentes, la clasificación en sí es capaz de abarcar a todas las entidades existentes o posibles de registrarse (OPS, 2017) ${ }^{18}$.

Otra limitación de las estadísticas de causas de muerte se refiere al cambio en la metodología aplicada en el país para codificar las muertes. Hubo una modificación a partir del año 1997 (utilizándose a partir de entonces la $10^{\circ}$ revisión), lo cual implicó la homologación de los grupos de causas para poder analizar la evolución durante el periodo analizado. En este sentido fue necesario agrupar las causas de muerte codificadas en ambas clasificaciones siguiendo los lineamientos de OPS (2017) en relación a la lista de mortalidad según causas seleccionadas de Argentina y la propuesta por Morales (Morales et al. 2005). La tabla 2 exhibe los grupos constituidos y las causas incluidas dentro de cada clasificación.

18 Las categorías se organizan con un criterio estadístico basado en la salud pública. Si una enfermedad es poco frecuente pero muy relevante desde el punto de vista de la salud de la población, tiene su propia categoría; lo mismo sucede con aquellas entidades de alta frecuencia. Asimismo, hay afecciones que serán representadas en una categoría junto a otras afecciones relacionadas. Por otro lado, la clasificación también prevé categorías residuales para aquellos diagnósticos que no pueden ser ubicados en categorías específicas. Además del agrupamiento de diagnósticos, la CIE ha establecido lineamientos para estandarizar el registro y la codificación, tanto de las afecciones mórbidas como de las causas de muerte, y reglas para seleccionar la causa básica de defunción (CBD) y la afección principal en los registros de morbilidad (OPS, 2017). 
Fernando Longhi - Sebastian Bianchi

Soja, glifosato y salud humana. Algunas evidencias en el Chaco Seco Argentino (1990 - 2012)

Tabla 2. Homologación de causas de muerte en grupos según Clasificación Internacional de Enfermedades (CIE) $9^{\circ}$ Revisión y CIE $10^{\circ}$ Revisión.

\begin{tabular}{|c|c|c|}
\hline \multicolumn{2}{|c|}{ CAUSA DE MUERTE } & \multirow[b]{2}{*}{ CODIGO CIE-10 } \\
\hline $\begin{array}{c}\text { DESCRIPCION } \\
\end{array}$ & CODIGO CIE- 9 & \\
\hline $\begin{array}{l}\text { CIERTAS ENFERMEDADES } \\
\text { INFECCIOSAS }\end{array}$ & $1-139$ & A00-B99 \\
\hline Enf. infecciosas intestinales & $001-009,136.5$ & A00-A09 \\
\hline Tuberculosis & 010-018 & A15-A19 B90 \\
\hline Tétanos & 037 & A33-A35 \\
\hline Septicemias & 038 & A40-A41 \\
\hline Infección meningocócica & 036 & A39 \\
\hline Meningitis viral & 047-049 & A87 \\
\hline Sarampión & 055 & B05 \\
\hline Dengue & 061 & A90-A91 \\
\hline Rubéola & 056 & B06 \\
\hline Hepatitis viral & 070 & B15-B19 \\
\hline $\begin{array}{l}\text { Enf. por Virus de la Inmunodeficiencia } \\
\text { Humana (VIH) }\end{array}$ & 279 & B20-B24 \\
\hline Tripanosomiasis & 086 & B57 \\
\hline $\begin{array}{l}\text { Las demás enfermedades infecciosas y } \\
\text { parasitarias }\end{array}$ & Resto 1-139 & $\begin{array}{l}\text { Todas las demás catego- } \\
\text { rías A y B }\end{array}$ \\
\hline TUMORES 140-239 & & C00-D48 \\
\hline Malignos- & $140-208$ & $\mathrm{C} 00-\mathrm{C} 97$ \\
\hline Esófago & 150 & $\mathrm{C} 15$ \\
\hline Estómago & 151 & $\mathrm{C} 16$ \\
\hline $\begin{array}{l}\text { Colon, recto y de la porción rectosigmoi- } \\
\text { dea y ano }\end{array}$ & $153-154$ & $\mathrm{C} 18-\mathrm{C} 21$ \\
\hline $\begin{array}{l}\text { Hígado y de los conductos biliares } \\
\text { intrahepáticos }\end{array}$ & 155 & $\mathrm{C} 22$ \\
\hline $\begin{array}{l}\text { Vesícula biliar y otras partes de las vías } \\
\text { biliares }\end{array}$ & 156 & $\mathrm{C} 23-\mathrm{C} 24$ \\
\hline Páncreas & 157 & $\mathrm{C} 25$ \\
\hline Traquea, de los bronquios y del pulmón & 162 & C33-C34 \\
\hline Mama & $174-175$ & C50 \\
\hline Útero & $179-182$ & C53-C55 \\
\hline Ovario & 183 & C56 \\
\hline Próstata & 185 & C61 \\
\hline $\begin{array}{l}\text { Riñón y otros órganos urinarios excepto } \\
\text { vejiga }\end{array}$ & 189 & C64-C66; C68 \\
\hline Vejiga urinaria & 188 & C67 \\
\hline $\begin{array}{l}\text { Encéfalo y otras partes del sistema nervio- } \\
\text { so central }\end{array}$ & 191 & $\mathrm{C} 69-\mathrm{C} 72$ \\
\hline Linfoma no Hodgkin & 201 & C82-C85 \\
\hline
\end{tabular}


Fernando Longhi - Sebastian Bianchi Soy, glyphosate and human health. Some evidence in the Argentinian Dry Chaco Region (1990-2012)

\begin{tabular}{|c|c|c|}
\hline \multicolumn{2}{|c|}{ CAUSA DE MUERTE } & \multirow[b]{2}{*}{ CODIGO CIE-10 } \\
\hline \begin{tabular}{|l|l|} 
DESCRIPCION \\
\end{tabular} & CODIGO CIE- 9 & \\
\hline Leucemias & $204-207$ & C91-C95 \\
\hline Tumor maligno de sitios no especificados & 199 & $\mathrm{C} 80$ \\
\hline Todos los demás tumores malignos & Resto $140-208$ & $\begin{array}{l}\text { Todas las demás cate- } \\
\text { gorías C }\end{array}$ \\
\hline $\begin{array}{l}\text { Carcinomas in situ, tumores benignos y de } \\
\text { comportamiento incierto o desconocido }\end{array}$ & $210-239$ & D00-D48 \\
\hline DIABETES MELLITUS & 250 & E10-E14 \\
\hline $\begin{array}{l}\text { DEFICIENCIAS DE LA NUTRICION } \\
\text { Y ANEMIAS NUTRICIONALES }\end{array}$ & $260-269 ; 280-281$ & E40-E64 D50-D53 \\
\hline TRASTORNOS METABÓLICOS & $270-277$ & E70 -E90 \\
\hline MENINGITIS & $320-322$ & G00-G03 \\
\hline ENFERMEDAD DE ALZHEIMER & 290,331 & G30 \\
\hline $\begin{array}{l}\text { ENFERMEDADES MENTALES Y DEL } \\
\text { COMPORTAMIENTO }\end{array}$ & 291-319 & F00-F99 \\
\hline Síndrome de dependencia del alcohol & 303 & F10 \\
\hline $\begin{array}{l}\text { ENFERMEDADES DEL SIST. } \\
\text { CIRCULATORIO }\end{array}$ & $390-459$ & I00-I99 \\
\hline Enfermedades Hipertensivas & $402-404$ & I10-I14 \\
\hline Enfermedades isquémicas del corazón & $410,413-414$ & $\mathrm{I} 20-\mathrm{I} 25$ \\
\hline Insuficiencia cardíaca & 428 & $\mathrm{I} 50$ \\
\hline Las demás enfermedades del corazón & Resto $390-429$ & $\begin{array}{l}\text { Las demás categorías } \\
\text { I00-I52 }\end{array}$ \\
\hline Enfermedades Cerebrovasculares & $430-438$ & I60-I69 \\
\hline Arterosclerosis & 440 & $\mathrm{I} 70$ \\
\hline Demás enfermedades del Sist. Circulatorio & Resto 390-459 & $\begin{array}{l}\text { Todas las demás cate- } \\
\text { gorías I }\end{array}$ \\
\hline $\begin{array}{l}\text { ENFERMEDADES DEL SIST. } \\
\text { RESPIRATORIO }\end{array}$ & $460-519$ & J00-J99 \\
\hline Neumonía e influenza & $480-487 ; 514$ & J09-J18 \\
\hline Bronquitis y bronquiolitis aguda & 466 & J20-J21 \\
\hline Las demás infecciones respiratorias agudas & Resto $460-466$ & $\begin{array}{l}\text { Las demás categorías } \\
\text { J00-J22 }\end{array}$ \\
\hline $\begin{array}{l}\text { Enf. crónicas de las vías respiratorias } \\
\text { inferiores }\end{array}$ & $\mathrm{J} 40-\mathrm{J} 47$ & $490-493$ \\
\hline Neumonitis debidas a sólidos y líquidos & 507 & J69 \\
\hline $\begin{array}{l}\text { Insuficiencia respiratoria no clasificada en } \\
\text { otra parte }\end{array}$ & 519 & J96 \\
\hline $\begin{array}{l}\text { Las demás enfermedades del sistema } \\
\text { respiratorio }\end{array}$ & Resto $460-519$ & $\begin{array}{l}\text { Todas las demás cate- } \\
\text { gorías J }\end{array}$ \\
\hline $\begin{array}{l}\text { APENDICITIS, HERNIA DE LA CAVI- } \\
\text { DAD ABDOMINAL Y OBSTRUCCION } \\
\text { INTESTINAL }\end{array}$ & $540-553 ; 560$ & K35-K46; K56 \\
\hline
\end{tabular}


Fernando Longhi - Sebastian Bianchi

Soja, glifosato y salud humana. Algunas evidencias en el Chaco Seco Argentino (1990 - 2012)

\begin{tabular}{|c|c|c|}
\hline \multicolumn{2}{|c|}{ CAUSA DE MUERTE } & \multirow[b]{2}{*}{ CODIGO CIE-10 } \\
\hline DESCRIPCION & CODIGO CIE- 9 & \\
\hline ENFERMEDADES DEL HIGADO & $570-573$ & K70-K77 \\
\hline $\begin{array}{l}\text { Ciertas enfermedades crónicas del hígado } \\
\text { y cirrosis }\end{array}$ & $571-573$ & $\mathrm{~K} 70 ; \mathrm{k} 73-\mathrm{k} 74 ; \mathrm{k} 76$ \\
\hline $\begin{array}{l}\text { ENFERMEDADES DEL SISTEMA } \\
\text { URINARIO }\end{array}$ & $580-629$ & N00-N39 \\
\hline Nefritis y nefrosis & $580-589$ & $\begin{array}{l}\text { N00-N07; N17-N19; } \\
\text { N25-N27 }\end{array}$ \\
\hline $\begin{array}{l}\text { Las demás enfermedades del sistema } \\
\text { urinario }\end{array}$ & Resto 580- 629 & $\begin{array}{l}\text { Todas las demás catego- } \\
\text { rias N00-N39 }\end{array}$ \\
\hline $\begin{array}{l}\text { COMPLICACIONES DEL EMBARA- } \\
\text { ZO, PARTO Y PUERPERIO }\end{array}$ & $630-676$ & O00-099 \\
\hline ANOMALIAS CONGENITAS & $740-759$ & Q00-Q99 \\
\hline $\begin{array}{l}\text { CIERTAS AFECCIONES ORIGINA- } \\
\text { DAS EN EL PERIODO PERINATAL }\end{array}$ & $760-779$ & P00-P96 \\
\hline CAUSAS EXTERNAS & 800-999 & V01-Y98 \\
\hline $\begin{array}{l}\text { Accidentes de Trafico de vehículo de } \\
\text { motor }\end{array}$ & $800-825$ & $\begin{array}{l}\text { V02-V04 con cuarto } \\
\text { dígito } 1 \text { ó 9; V051; } \\
\text { V092 y V093; V12-V15 } \\
\text { y V20-V28 con } \\
\text { cuarto dígito 4, } 5 \text { ó 9; } \\
\text { V30-V38, V40-V48, } \\
\text { V50-V58, V60-V68, } \\
\text { V70-V78 con cuarto } \\
\text { dígito 5, 6, } 7 \text { ó 9; V19, } \\
\text { V29, V39, V49, V59, } \\
\text { V69 y V79 con cuarto } \\
\text { dígito 4, 5, 6 ó } \\
\text { 9; V803 - V805; V811; } \\
\text { V821; V830-V833; } \\
\text { V840-V843 ; V850- } \\
\text { V853; V860 - V863; } \\
\text { V870 } \\
\text { - V878; V892 y V899 }\end{array}$ \\
\hline $\begin{array}{l}\text { Otros accidentes de transporte, inclusive } \\
\text { secuelas }\end{array}$ & Resto $800-848$ & $\begin{array}{l}\text { Las demás categorías } \\
\text { V01-V99; Y85 }\end{array}$ \\
\hline Ahogamiento y Sumersión Accidental & 910 & W65-W74 \\
\hline $\begin{array}{l}\text { Otras causas externas de traumatismos } \\
\text { accidentales, inclusive secuelas }\end{array}$ & $880-888 ; 929$ & $\begin{array}{l}\text { W00-W64; W75-X58; } \\
\text { Y86 }\end{array}$ \\
\hline Suicidios, inclusive secuelas & $950-959$ & $\mathrm{X} 60-\mathrm{X} 84$ \\
\hline Agresiones, inclusive secuelas & $960-969$ & X85-Y09; Y871 \\
\hline $\begin{array}{l}\text { Eventos de Intención no determinada, } \\
\text { inclusive secuelas }\end{array}$ & $980-989$ & Y10-Y34; Y872 \\
\hline
\end{tabular}


Fernando Longhi - Sebastian Bianchi Soy, glyphosate and human health. Some evidence in the Argentinian Dry Chaco Region (1990-2012)

\begin{tabular}{|l|l|l|}
\hline \multicolumn{2}{|c|}{ CAUSA DE MUERTE } & \multicolumn{1}{|c|}{ CODIGO CIE-10 } \\
\hline $\begin{array}{l}\text { Complicaciones de la atención medica y } \\
\text { quirúrgica } \\
\text { Demás causas externas }\end{array}$ & $870-879$ & Y40-Y84 \\
DEMAS CAUSAS DEFINIDAS & Resto $800-899$ & $\begin{array}{l}\text { Todas las demás catego- } \\
\text { rías V01-Y98 } \\
\text { Resto de categorias, } \\
\text { excepto R00-R99 } \\
\text { R00-R99 }\end{array}$ \\
MAL DEFINIDAS Y DESCONOCIDAS & Resto excepto 800-899-799 & $\mathbf{7 8 0 9}$ \\
\hline
\end{tabular}

Fuente: OPS (2017) y Morales et al. (2005). Elaboración propia

De acuerdo a esta construcción, se observa que el perfil general en los veintidós años que van de 1990 a 2012, destaca la preeminencia de causas relacionadas con el aparato circulatorio ( $21 \%$ de las defunciones) (Figura 2). Le siguen en importancia los tumores (17.6\%), causas externas $(10.4 \%)$, enfermedades respiratorias $(9.9 \%)$, estados morbosos mal definidos $(8 \%)$ e infecciosas $(8 \%)$.

Figura 2. Chaco Seco Argentino. Perfil epidemiológico general. (1990 - 2012)

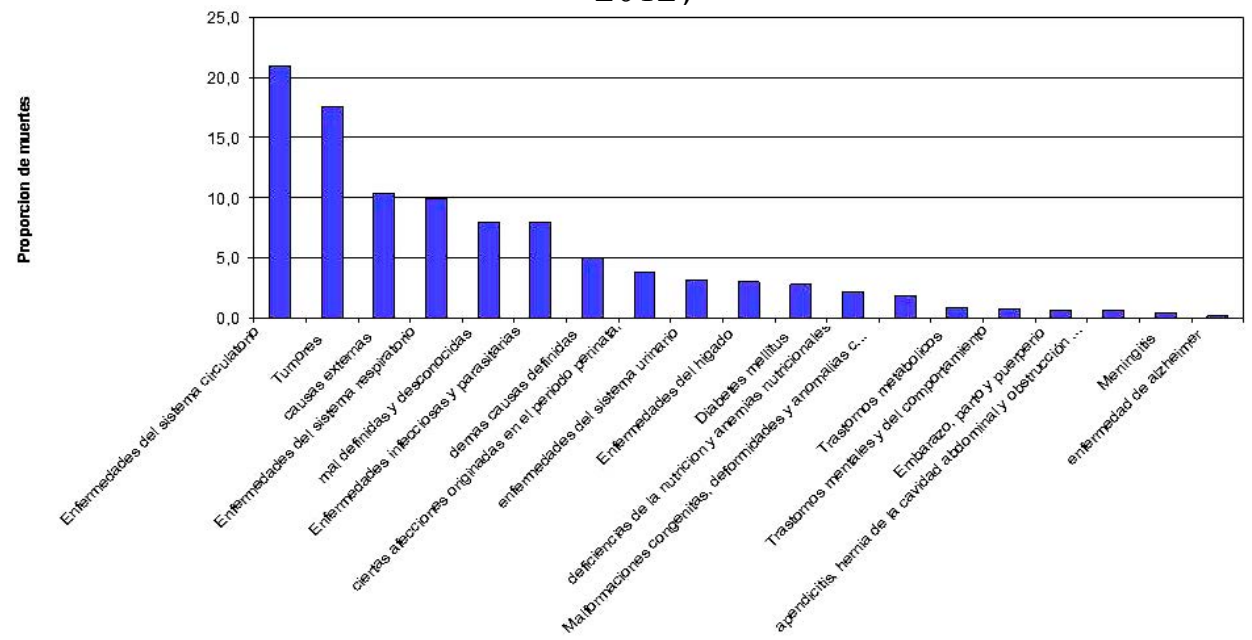

Fuente: Estadísticas Vitales 1990-2012. Elaboración propia

Las figuras 3, 4 y 5 presentan la evolución de todos los grupos de causas entre 1990 y 2012. Se observa un patrón acorde con la transición epidemiológica argentina. 
Fernando Longhi - Sebastian Bianchi

Soja, glifosato y salud humana. Algunas evidencias en el Chaco Seco Argentino (1990 - 2012)

Figura 3. Chaco Seco Argentino. Evolución de grupos de causas de muerte seleccionados (1990 - 2012).

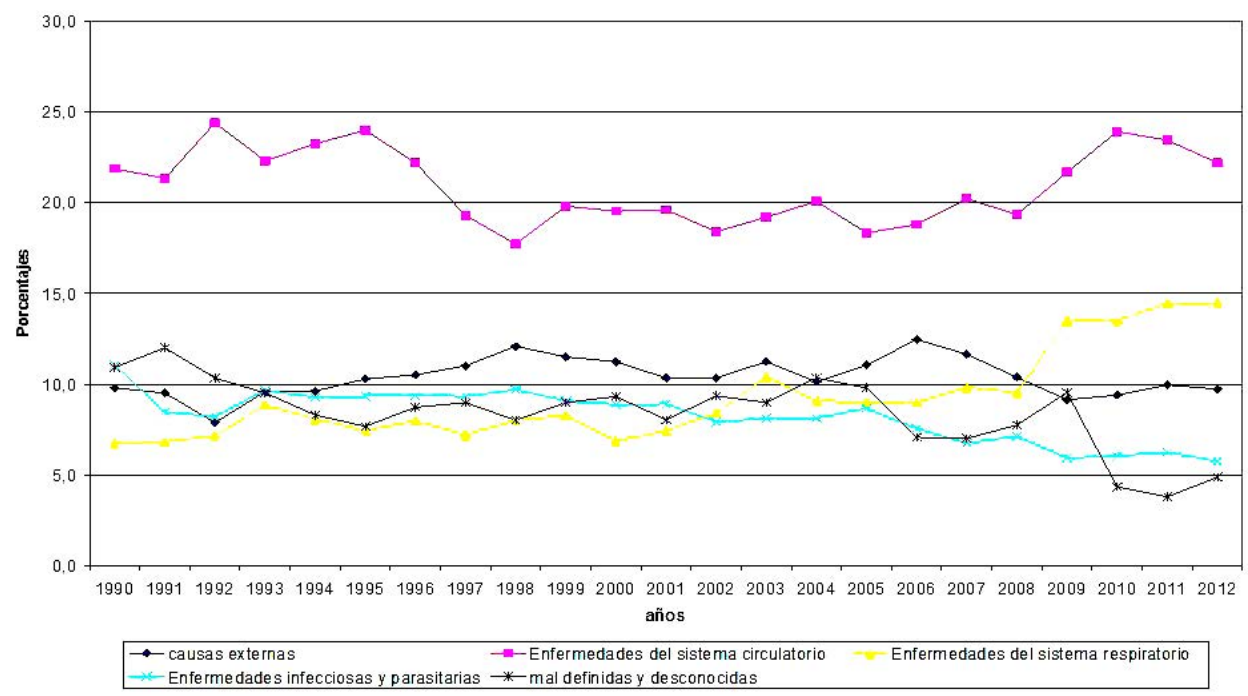

Fuente: Estadísticas Vitales 1990-2012. Elaboración propia

Figura 4. Chaco Seco Argentino. Evolución de grupos de causas de muerte seleccionados (1990 - 2012).

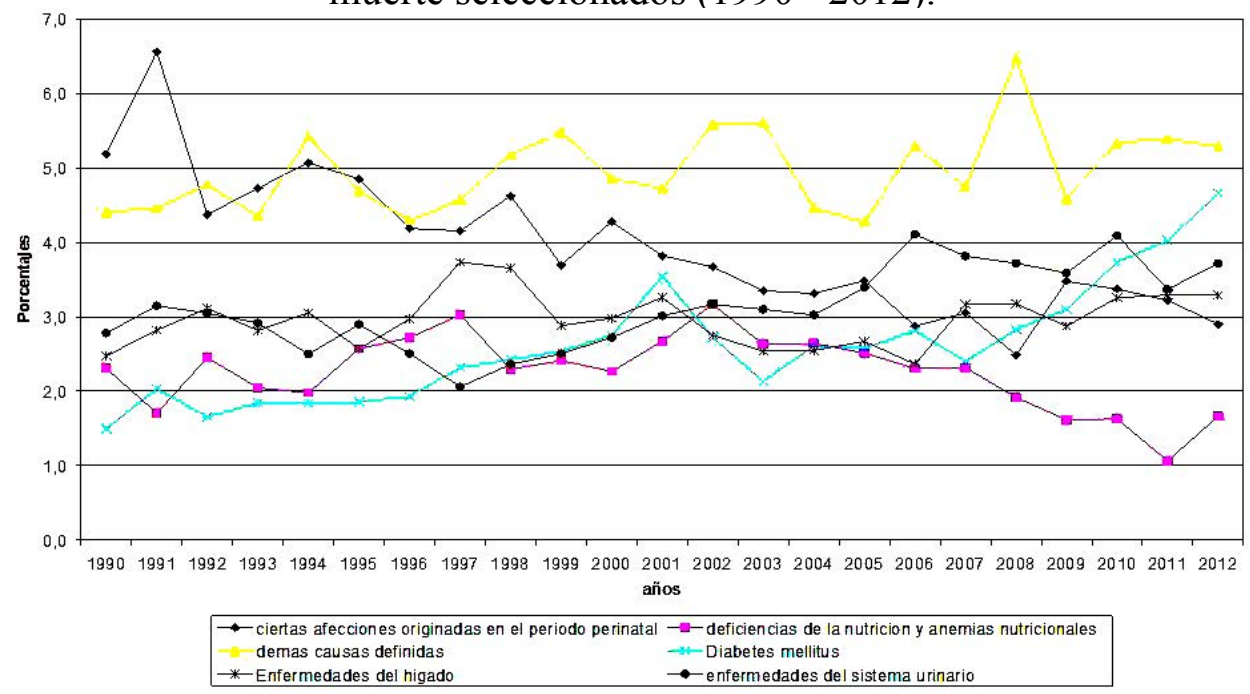

Fuente: Estadísticas Vitales 1990-2012. Elaboración propia 
Figura 5. Chaco Seco Argentino. Evolución de grupos de causas de muerte seleccionados $(1990$ - 2012).

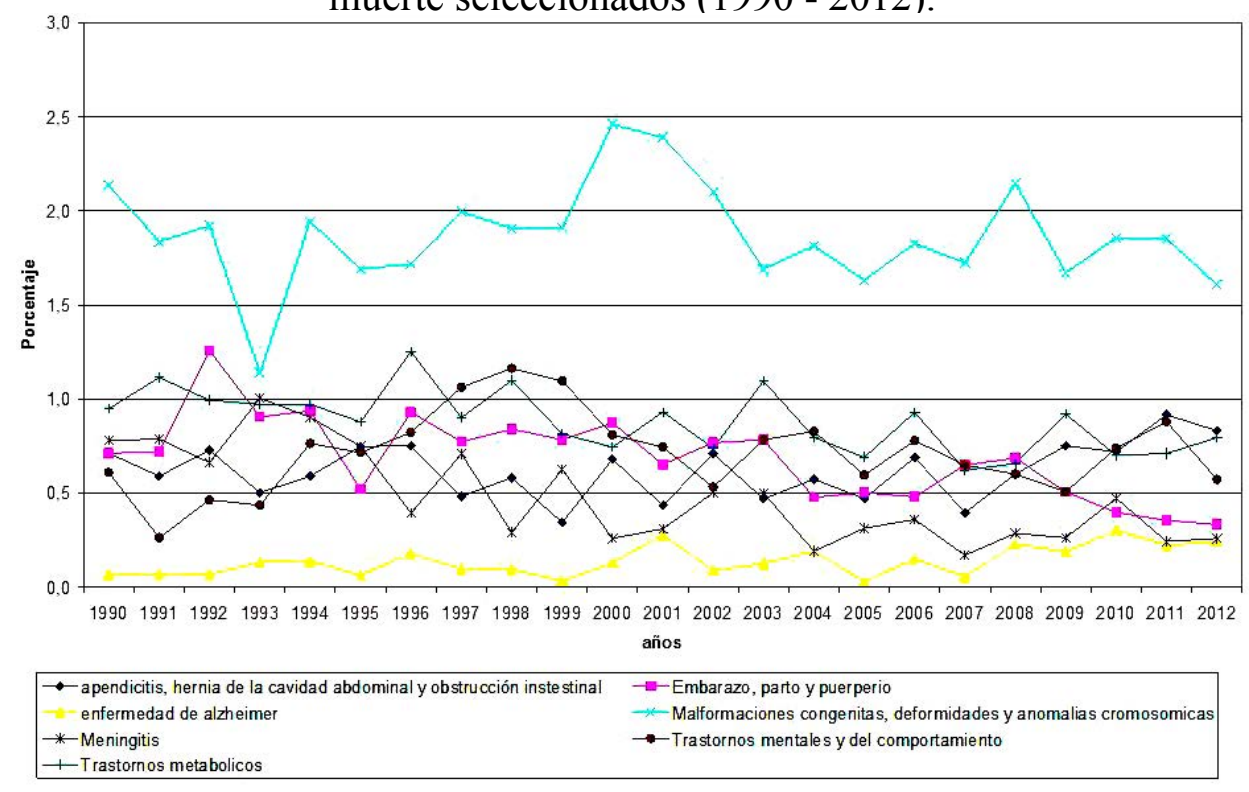

Fuente: Estadísticas Vitales 1990-2012. Elaboración propia

A partir de este análisis es posible detectar que los grupos de causas que han presentado una tendencia mayor al aumento son la enfermedad de Alzheimer (51\% de variación relativa), meningitis (8.4\%), apendicitis (7\%) y diabetes mellitus (6.5\%). Por otro lado, los grupos que más han disminuido son las enfermedades infecciosas y parasitarias $(-2.5 \%)$, las mal definidas $(-1.6 \%)$ y las afecciones originadas en el periodo perinatal (-1.4\%), proceso coincidente con los postulados del modelo de transición epidemiológica.

\section{El perfil epidemiológico regional según niveles de glifosización}

De las hipótesis de investigación planteadas podrían esperarse ciertas evidencias estadísticas. Una de ellas sería una relación directa entre las tasas de mortalidad en relación a cada nivel IRSAG, es decir, a mayor nivel IRSAG, mayores tasas, sobre todo a partir del año 1996 (momento a partir se inicia el cultivo de soja transgénica).

Otro indicio que sostendría las conjeturas sería una variación en la pendiente de la tasa de mortalidad (independientemente de su magnitud) a 
partir del año 1996 o años subsiguientes, que sería indicador de un cambio del perfil epidemiológico. Por último, dichas tasas deberían mostrar también una relación directa con los niveles de IRSAG (a mayor nivel, mayor pendiente) a pesar de que no se evidenciara ningún quiebre significativo en todo el período.

Si prestamos atención a la relación entre los niveles del IRSAG definidos con anterioridad y determinadas causas de muertes específicas, tales como tumores, linfoma no hodgkin, enfermedad de Alzheimer y anomalías congénitas (todas asociadas a efectos del glifosato según los antecedentes revisados) encontramos los resultados que se presentan a continuación. Como puede observarse no hallamos asociación significativa entre los niveles de glifosización y el aumento de causas de muerte que podrían estar asociadas a dicho químico. Las causas analizadas tanto en magnitud, tendencias y ritmo de crecimiento no han mostrado asociación con el creciente proceso de sojización del Chaco Argentino.

La categoría tumores -aquella más estudiada en la bibliografía por su posible relación con el glifosato- exhibe claramente un comportamiento creciente durante todo el periodo en todos los niveles, no obstante se puede distinguir, en el nivel 5, una clara ruptura de la tendencia en el año 1999 (figura 6), mostrando a partir de entonces -y a diferencia del comportamiento anterior- una clara pendiente ascendente. Si bien esto no constituye una prueba concluyente de la correlación esperada, si se destaca como un argumento que sostiene parte de las hipótesis planteadas. Por otro lado, si comparamos las tendencias para los tres niveles en el período 2000-2012 (figura 9), si bien se observa que los valores absolutos de las tasas de mortalidad por tumores para los niveles 1 y 3 son mayores que para el nivel 5, en este último la tendencia al aumento de estas patologías es claramente mayor.

Se analizaron también las tasas de mortalidad por enfermedad de Alzheimer y Linfoma No Hodgkin en la región, sin embargo, las escasas muertes registradas por estas patologías atentan contra el análisis estadístico, impidiendo poder establecer tanto una tendencia de evolución definida como una correlación clara con los niveles IRSAG (figuras 10 a 17).

Finalmente, en cuanto a malformaciones congénitas, las figuras 18 a 20 exhiben que a medida que aumenta el nivel IRSAG, menor es la pendiente de variación de la mortalidad. Además, la Figura 21 muestra que los valores de la tasa de mortalidad son incluso mayores en los niveles 1 y 3 
que en el nivel 5 para casi todo el período. Ambos comportamientos son opuestos a lo esperado según las hipótesis de investigación planteadas.

No obstante, la valoración general de los resultados es mínimamente concluyente. El cambio de tendencia en la tasa de mortalidad por tumores en el mayor nivel de IRSAG en 1999 es claro para sostener esta valoración. Se conjetura que distintas líneas alternativas de trabajo nutrirían con más argumentos esta conjetura. Entre tales líneas una extensión en el lapso de estudio (que llega hasta 2012) podría generar dichos argumentos: también la aplicación del método desarrollado en otras regiones argentinas donde la soja transgénica tiene incluso un mayor protagonismo; finalmente, el estudio de la morbilidad de la población, a partir de las Estadísticas de Egresos Hospitalarios elaboradas por la Dirección de Estadísticas de Salud del Ministerio de Salud de la Nación, podría argumentar la relación glifosato-salud con mayores evidencias, sin llegar al caso extremo aquí analizado como lo es la muerte.

Figura 6. Tasa de mortalidad por tumores período 1990-2012 según niveles 5, 3 y de IRSAG y comparación de tendencias (2000-2012)
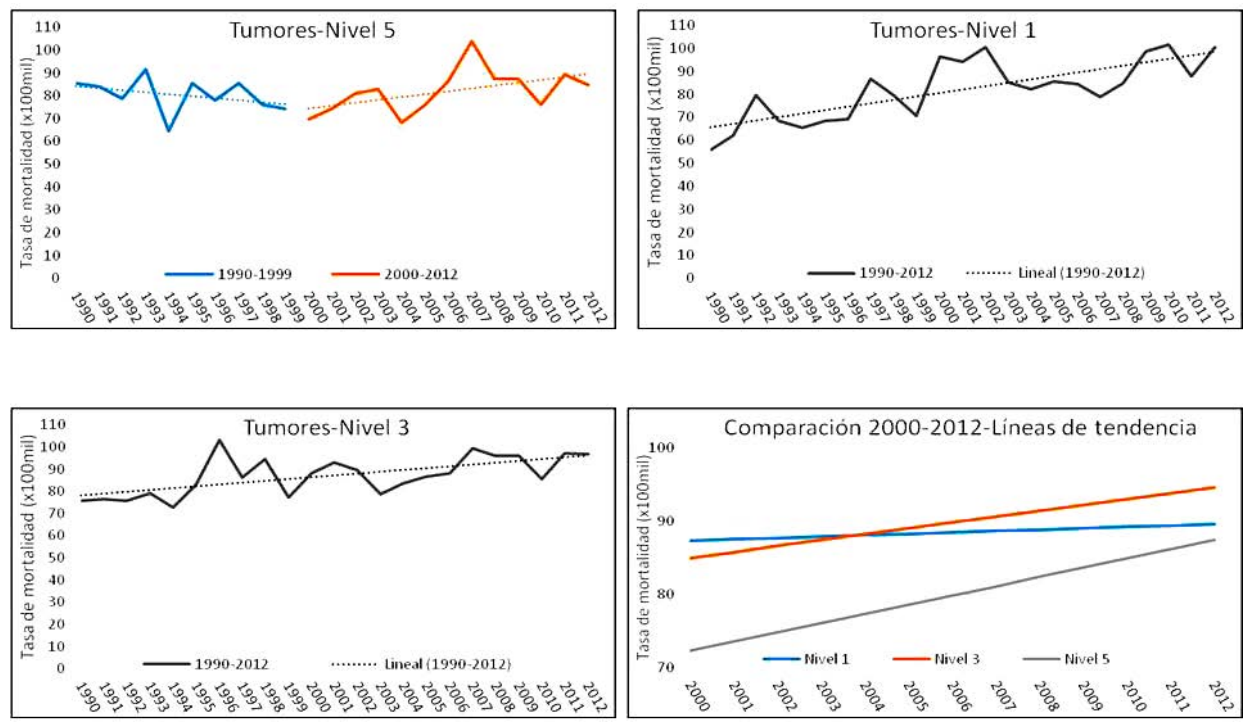

Elaboración propia sobre la base del Programa Nacional de Estadísticas de Salud 
Fernando Longhi - Sebastian Bianchi

Soja, glifosato y salud humana. Algunas evidencias en el Chaco Seco Argentino (1990 - 2012)

Figura 7. Tasa de mortalidad por linfoma no Hodgkin período 1990-2012 según niveles 5, 3 y de IRSAG y comparación de niveles
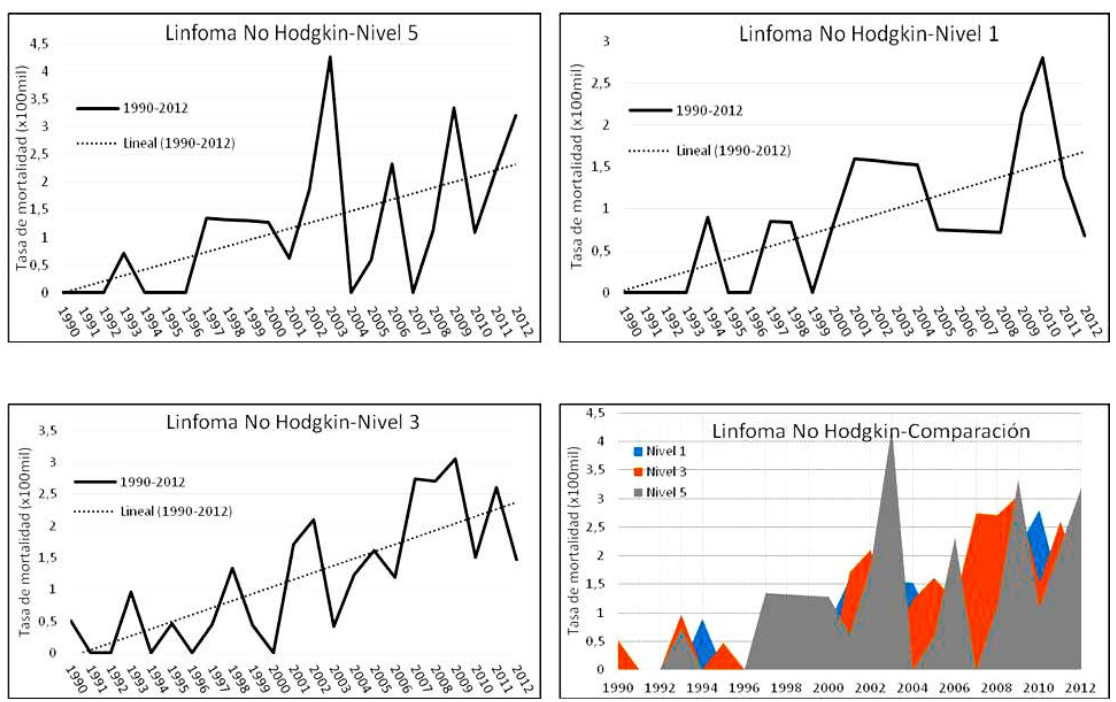

Elaboración propia sobre la base del Programa Nacional de Estadísticas de Salud

Figura 8. Tasa de mortalidad por enfermedad de Alzheimer período 1990-2012 según niveles 5, 3 y de IRSAG y comparación de niveles
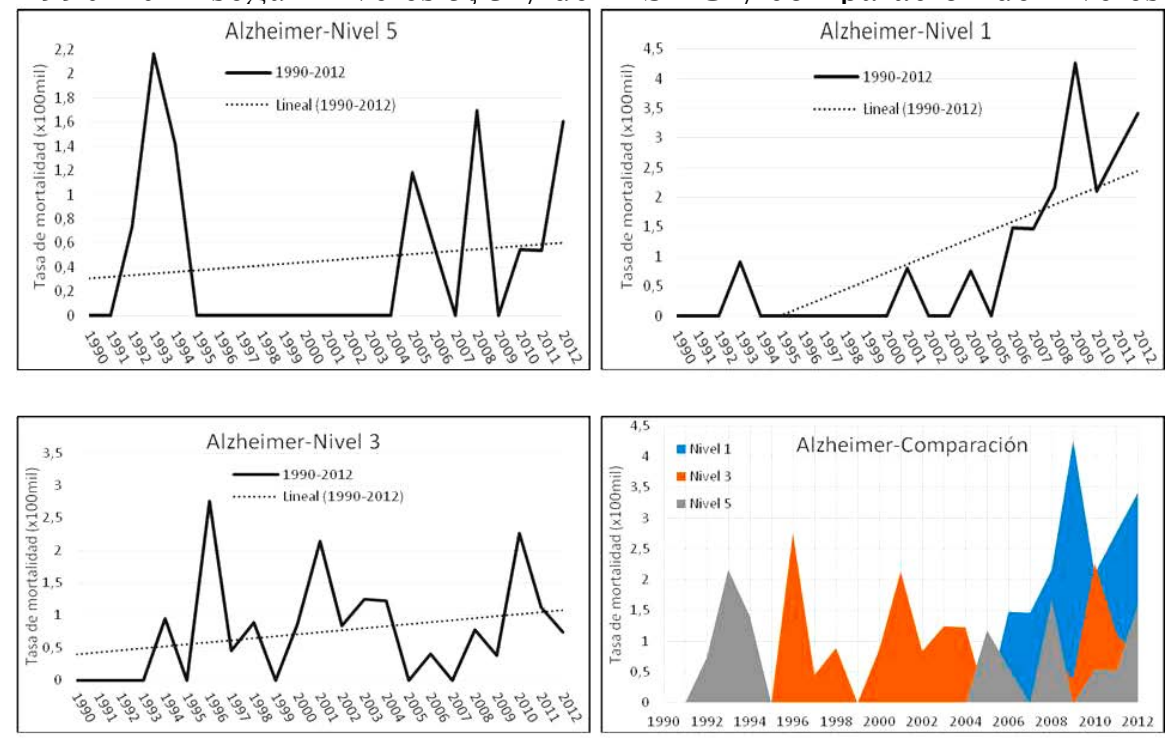

Elaboración propia sobre la base del Programa Nacional de Estadísticas de Salud 
Figura 9. Tasa de mortalidad por malformaciones congénitas período 1990-2012 según niveles 5, 3 y de IRSAG y comparación de niveles
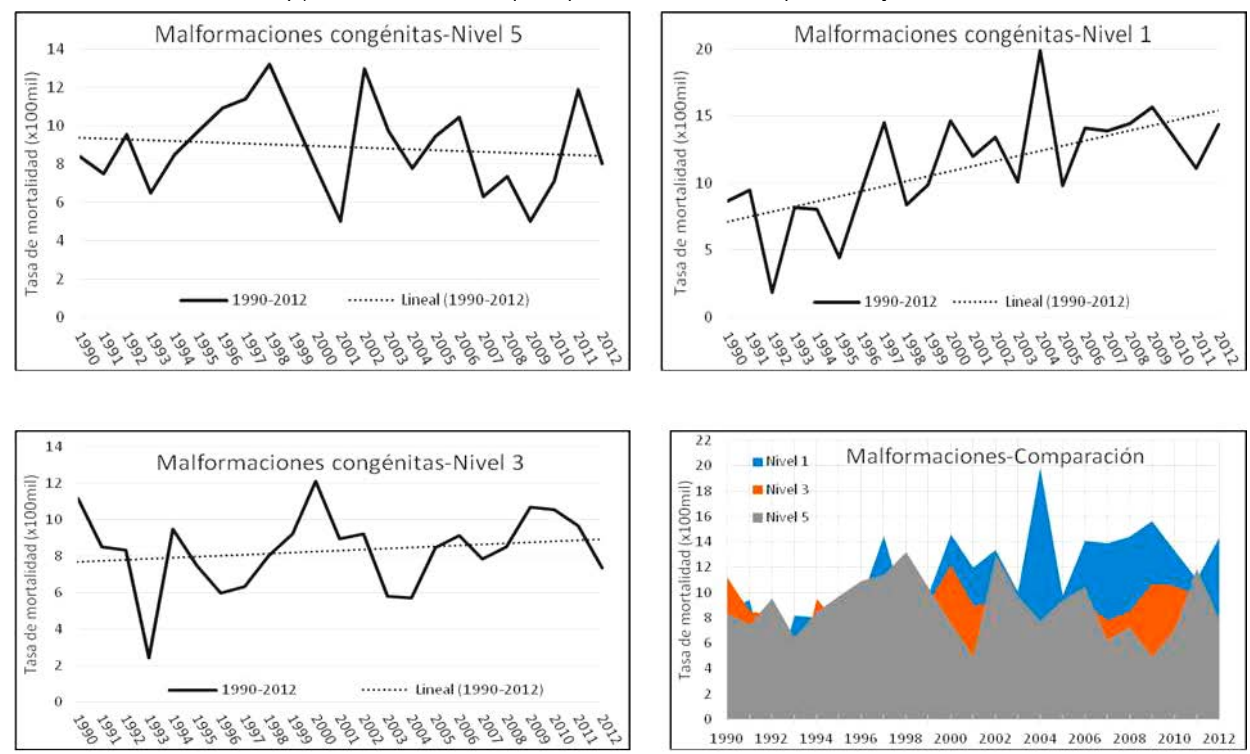

Elaboración propia sobre la base del Programa Nacional de Estadísticas de Salud

\section{Conclusiones}

El Chaco Seco Argentino constituye un territorio de trascendente trasformación productiva en las últimas décadas sin que ello lo haga abandonar su condición marginal en la estructura productiva argentina. Se suma a dicha condición el posible efecto que el glifosato -hermano dilecto de la soja transgénica- podría haber tenido sobre la salud de sus habitantes.

Ante la ausencia de investigaciones epidemiológicas que analicen esta relación se postuló una propuesta metodológica de análisis que operó estadísticamente sobre la base de las estadísticas vitales de mortalidad, consolidadas entre 1990 y 2012.

El objetivo que guio el análisis fue entonces la búsqueda de evidencia sobre la incidencia en la salud humana -a partir de un análisis epidemiológico- del glifosato como agente asociado al aumento de determinadas causas de muerte, tales como tumores, linfoma no Hodgkin, anomalías congénitas, abortos espontáneos y enfermedad de Alzheimer, todas asociadas desde el marco teórico con dicho agente contaminante. Dicho enfoque operó sobre la base de la única información de causas de muerte existentes (estadísticas 
vitales de mortalidad), las cuales, de acuerdo sus limitaciones intrínsecas, no permiten conocer ubicación residencial exacta del fallecido ni historia clínica del mismo, lo cual podría haber contribuido a detectar posibles variables confusoras. En virtud de todo lo mencionado detectamos que las evidencias halladas no son suficientes para concluir una relación estadísticamente significativa entre la exposición al agroquímico y su efecto.

En términos de mortalidad no es posible distinguir en este territorio una asociación entre el glifosato y la salud humana. Dicha asociación no se pudo establecer en términos de magnitud, tendencia ni tampoco en ritmo de crecimiento. Existe sólo una evidencia que se distinguió a favor de la hipótesis planteada, el cual argumenta un cambio ascendente en la tendencia de la mortalidad por tumores en el mayor nivel de IRSAG en 1999, coincidente con el momento de aplicación del herbicida. Más allá de esto no encontramos mayor asociación en ninguna de las patologías mencionadas, no obstante es preciso mencionar que en el caso específico de los abortos espontáneos -si hubiera relación- no podemos analizarla con las fuentes utilizadas, dado que el aborto -en cualquier momento de la gestación y en su condición de no nacido- no se registra en las estadísticas de mortalidad.

No obstante, dada la evidencia teórica existente, se sugiere profundizar en estudios futuros sobre dos líneas independientes: por un lado se estudiará según los niveles de IRSAG establecidos en el Chaco Seco la morbilidad de la población a partir de estadísticas de Egresos Hospitalarios; por otro lado, se continuará el análisis de la mortalidad en los departamentos argentinos donde los niveles del IRSAG alcancen los valores más elevados.

\section{Referencias}

Álvarez, C., Reynoso, M. V., Gómez, D., León, R., Canales, A. \& Feria, A. (2014). Comparision of the in vivo and in vitro genotoxicity of glyphosate isopropylamine salt in three different organisms. Genetics and Molecular Biology, 1 (37), 105-110.

Anadón, A., Martínez Larrañaga, M. R., Martinez, M. A., Castellano, V.,

Martínez, M., Martin, M. \& Bernal, J. (2009). Toxicokinetics of glyphosate and its metabolite aminomethyl phosphonic acid in rats. Toxicology Letters (190), 91-95. 
Benachour, N. \& Seralini, E. (2009). Glyphosate Formulations Induce Apoptosis and Necrosis in Human Umbilical, Embryonic, and Placental Cells. Chemical Research in Toxicology (22), 97-105.

Bravo, E. (2015). Un mal cabalga con el viento. La toxicidad y carcinogenicidad del glifosato. Quito: Third World Network.

Bravo, A.; Rodríguez, J.; Centurión Mereles, H.; Domínguez, D.; Bravo, M.; Sabatino, P.; \& Poth, C. (2010). Los señores de la soja: la agricultura transgénica en América Latina. CICCUS - CLACSO: Buenos Aires.

Bruniard, E. (1975/78). El gran Chaco argentino. UNNE: Resistencia.

Carrasco, A. (2010). Glyphosate-Based Herbicides Produce Teratogenetic Effects on Vertebrates by Imparing Retinoic Acid Signaling. Chemical Research in Toxicology (23), 1586-1595.

CNIA. (2009). Evaluación de la información científica vinculada al glifosato en su incidencia sobre la salud humana y el ambiente. Buenos Aires: Comisión Nacional de Investigaciones sobre Agroquímicos-CONICET.

Córdoba, A.; Leal, G. \& Martínez, C. (1989). El problema del diagnóstico médico en la investigación de la mortalidad por causa. En R. Jiménez Ornelas, Investigación multidisciplinaria de la mortalidad y morbilidad en niños menores de cinco años (Primer Seminario de Demografía Formal). México DF: UNAM / Centro de Investigaciones Multidisciplinarias, 39-46.

Domínguez, D. I. \& Sabatino, P. (2010). La muerte que viene en el viento. La problemática de la contaminación por efecto de la agricultura transgénica en Argentina y Paraguay. En A. L. Bravo, H. Centurión, D. I. Domínguez, P. Sabatino, C. M. Poth, \& J. L. Rodríguez, Los señores de la soja. La agricultura transgénica en América Latina (págs. 31-122). Buenos Aires: CLACSO.

EPA. (1997). Glyphosate; Pesticide Tolerances. Enviromental Protection Agency. US Federal Register.

Fernandez, J., Wechsler, S., Livingston, M. \& Mitchell, L. (2014). Genetically Engineered Crops in the United States. United States Department of Agriculture, Economic Research Service. Economic Research Report. 
Frenk, J., Frejka, T., Bobadilla, J. L., Stern, C., Lozano, R., Sepúlveda, J. \& José, M. (1991). La transición epidemiológica en América Latina. Bol. of. Sanit. Panam. 111, (6)

Giarracca, N. y Teubal, M. (2006). Democracia y neoliberalismo en el campo argentino. Una convivencia difícil", en GRAMMONT, H. (Ed.) $L a$ construcción de la democracia en el campo latinoamericano. Buenos Aires, CLACSO, Consejo Latinoamericano de Ciencias Sociales.

Gómez, S. (2017). Usos del territorio, acumulación por desposición y derecho a la salud en la Argentina contemporánea: el caso de la soja transgénica. Geographia, XIX (39), 3-15.

Ibáñez, M. (2002). ¿Qué usan en Colombia? El nuevo agente naranja. Efectos sobre la salud y el ambiente de herbicidas que contienen glifosato. En <www.rebelion.org $>$.

IARC-OMS. (2015). Carcinogenicity of tetrachlorvinphos, parathion, malathion, diazinon and glyphosate. IARC Monographs.

ISAAA. (2017). Global Status of Commercialized Biotech/GM Crops in 2017: Biotech Crop Adoption Surges as Economic Benefits Accumulate in 22 Years. ISAAA Briefs (53).

Mañas, F., Peralta, L., Ugnia, L., Weyers, A., García, H., \& Gorla, N. (2013). Oxidative stress and comet assay in tissues of mice administered glyphosate and AMPA in dringking water for 14 days. Journal of Basic \& Applied Genetics, XXIV (7), 67-75.

Morales, M. Á. M., Peña, E. Z., Mesa, A. C., Machado, D., \& Álvarez, R. C. (2005) Clasificación Internacional de Enfermedades y Problemas relacionados con la Salud.(CIE). Estudio comparativo entre revisiones sucesivas CIE-9 \& CIE-10. Experiencia Cubana. La Habana. Organización Panamericana de la Salud (OPS). (2017). Lineamientos básicos para el análisis de la mortalidad. Washington, D.C.

Ortega, L. (2014). La soja y el debate sobre el desmonte. Documentos de CEIA (10), 43-59.

Paolasso, P., Krapovickas, J. \& Gasparri, N. I. (2012). Deforestación, Expansión Agropecuaria y Dinámica Demográfica en el Chaco Seco Argentino Durante la Década de los Noventa. Latin American Research Review, 47 (1), 35-63.

Pengue, W. (2003). El glifosato y la dominación del ambiente. Biodiversidad (37), 1-7. 
Pizarro, J. (2003). La evolución de la producción agropecuaria pampeana en la segunda mitad del siglo XX. Revista Interdisciplinaria de Estudios Agrarios (18), 63-125.

Rodríguez, J. (2010). Consecuencias económicas de la difusión de la soja transgénica modificada en Argentina, 1996-2006. En A. L. Bravo, H. F. Centurion Mereles, D. I. Domínguez, P. Sabatino, C. M. Poth, \& J. L. Rodríguez, Los señores de la soja. La agricultura transgénica en América Latina (págs. 155-258). Buenos Aires: CLACSO.

Rofman, A. (1999). "Modernización productiva y exclusión social en las economías regionales". Revista Realidad Económica, $\mathrm{N}^{\circ} 162$, Argentina, Ed. IADE.

Samsel, A. \& Seneff, S. (2013). Glyphosate's Suppression of Cytochrome P450 Enzymes and Amino Acid Biosynthesis by the Gut Micribiome: Pathways to Modern Diseases. Entropy (15), 1416-1463.

Schinasi, L. \& Leon, M. (2014). Non-Hodgkin Lymphoma and Occupational Exposure to Agricultural Pesticide Chemical Groups and Active Ingredients: A Systematic Review and Meta-Analysis. International Journal of Enviromental Research and Public Health (11), 4449-4527.

Teubal, M. (2006). "Expansión del modelo sojero en la Argentina", en Revista Realidad Económica, No 220, Bs. As.

Torrella, S. A. \& Adámoli, J. (2005). Situación ambiental de la ecorregión del Chaco Seco. En La situación ambiental Argentina, 2005, 73-75.

Unión Europea. (2017). Preguntas y respuestas: la Comisión responde a la Iniciativa Ciudadana Europea sobre el glifosato y anuncia más transparencia en las evaluaciones científicas. Estrasburgo: Unión Europea. Hoja informativa.

Van Dam, C. (2002). Ocupación, degradación ambiental, cambio tecnológico y desarrollo sostenible: los efectos de la introducción del paquete soja/siembra directa en el chaco salteño. Tesis de Maestría, FLACSO.

Williams, G., Kroes, R. \& Munro, I. (2000). Safety Evaluation and Risk Assessment of the Herbicide Roundup and Its Active Ingredient, Glyphosate, for Humans. Regulatory Toxicology and Pharmacology (31), 117-165. 